\title{
A Case of Conversion Catatonia Misdiagnosed for 24 Years
}

Pauline K. Wiener, M.D.

St. Vincents Hospital and Medical Center, New York, New York

Follow this and additional works at: https://jdc.jefferson.edu/jeffjpsychiatry

Part of the Psychiatry Commons

Let us know how access to this document benefits you

\section{Recommended Citation}

Wiener, M.D., Pauline K. (1990) "A Case of Conversion Catatonia Misdiagnosed for 24 Years," Jefferson Journal of Psychiatry. Vol. 8 : Iss. 1 , Article 10.

DOI: https://doi.org/10.29046/JJP.008.1.005

Available at: https://jdc.jefferson.edu/jeffjpsychiatry/vol8/iss1/10

This Article is brought to you for free and open access by the Jefferson Digital Commons. The Jefferson Digital Commons is a service of Thomas Jefferson University's Center for Teaching and Learning (CTL). The Commons is a showcase for Jefferson books and journals, peer-reviewed scholarly publications, unique historical collections from the University archives, and teaching tools. The Jefferson Digital Commons allows researchers and interested readers anywhere in the world to learn about and keep up to date with Jefferson scholarship. This article has been accepted for inclusion in Jefferson Journal of Psychiatry by an authorized administrator of the Jefferson Digital Commons. For more information, please contact: JeffersonDigitalCommons@jefferson.edu. 


\title{
A Case of Conversion Catatonia Misdiagnosed for 24 Years
}

\author{
Pauline K. Wiener, M.D.
}

\section{INTRODUCTION}

Catatonia is a syndrome whose etiology may be both diverse and difficult to substantiate. Ms. H. is a 45-year-old black female with 18 previous psychiatric hospitalizations beginning at age 21 . A common characteristic to all hospitalizations was a catatonic presentation (i.e., the patient was mute with marked muscular rigidity; she would refuse to eat or follow orders). In each of her previous 18 hospitalizations, the patient was thought to be psychotic.

It was found that each catatonic episode could be related to a severe psychological stressor. The patient's illness never involved delusions, hallucinations or disturbances in thought form. Upon detailed evaluation of this patient's history she was found to have symptoms consistent with conversion disorder.

I report here the identification of a conversion disorder presenting as recurrent episodes of catatonia. Intramuscular lorazepam was found to be repeatedly successful in resolving the catatonic state.

\section{CASE REPORT}

Ms. H., a 45-year-old, separated, black female presented to the psychiatric ward with a one-week history of catatonia. On presentation, Ms. H. maintained an alert but blank facial expression; her eyes were open but there was no eye contact. While being carried on the stretcher she was nearly dropped and gave out a loud fearful expression.

For the past 3 years the patient had lived in a residential facility where her psychiatrist prescribed fluphenazine and from time to time she would have catatonic episodes lasting up to 4 weeks. Between these episodes the patient was popular and gregarious. The patient revealed later in her hospitalization that immediately prior to entering into her catatonic state she was devastated by her boyfriend's flirting with other female patients at the residential facility. Vital signs and the physical examination were within normal limits with the exception of the patient's muscular rigidity, marked resistance to any movement and inability to comply with parts of the neurologic exam. Laboratory values including serum electrolytes, complete blood count, thyroid function test, RPR and urinalysis were normal.

Ms. H.'s diagnoses from her previous hospitalizations included eight diagnoses of catatonic schizophrenia, four of undifferentiated schizophrenia, two of unspecified psychosis, and two of schizoaffective disorder. In each previous hospitalization the patient presented with varying periods of catatonia lasting from 3 days to 4 weeks, but never was there any evidence of delusions, hallucinations or formal thought disorder. Various 
antipsychotic medications failed to resolve any of the catatonic states. The patient developed a 2-week episode of unexplained right-sided hemiparesis and a 2-day episode of globus hystericus after a stressful argument. In addition, she developed a one year episode of vaginismus following a miscarriage in 1973. The patient's family situation was chaotic due to both parents being alcoholics. There was otherwise no family history of psychiatric illness. The patient received a business degree and worked as a bookkeeper for many years. She married at age 21 and separated 16 years later. The patient was physically abused by her husband for the last 12 years of their marriage.

Thirteen days into the hospital course fluphenazine was discontinued. Three days later the catatonia spontaneously resolved: the patient was talking, showed no physical rigidity and began eating. Ms. H. continued to do well for approximately one week until she experienced several stressors. She was informed that her mother had died that week. In addition, several expected visitors failed to show up. Over the next week the patient became more seclusive, and eventually re-entered her catatonic state.

This latest catatonic state lasted 9 days at which time it was decided to administer IM lorazepam ( $2 \mathrm{mg}$. every 8 hours). Several hours after the second dose the patient's catatonia spontaneously resolved. The patient explained how she felt prior to entering the catatonic state: "I felt down ... My mother's death upset me. My husband did not come and visit me like he said he would. My heart felt heavy. I escaped into silence, like lights out."

When not catatonic, the patient displayed no disturbances in perception, thought form or thought content. Her affect was appropriate, she had a sense of self and showed no impairment in role functioning. She showed interest in activities, was goal-directed, and exhibited no impairment in interpersonal functioning.

The patient had 2 additional catatonic episodes over the last 2 weeks of her hospitalization. In each episode a response was seen after two IM injections of lorazepam. The patient was discharged on $2 \mathrm{mg}$. of IM lorazepam to be used every eight hours as needed for her intermittent catatonic states. Following discharge, the patient did well, but continued to have catatonic episodes following stressors. These episodes rapidly responded to IM lorazepam.

\section{DISCUSSION}

Catatonia is a syndrome with multiple causes. Organic causes include neurologic disorders $(1,2)$, metabolic disturbances, intoxication and pharmacologic agents $(3,4,5)$. Psychogenic causes include schizophrenia (6), reactive psychosis, major depression, bipolar disorder (7), conversion disorder (8), and dissociative states. Abrams and Taylor (9), studied 55 patients with catatonia and found that more than $66 \%$ had affective illness, $9 \%$ were diagnosed as having neurologic disorders, $7 \%$ were diagnosed as having schizophrenia, and $5 \%$ had reactive psychoses.

This patient had been misdiagnosed as psychotic for the past 24 years; catatonic schizophrenia was the most frequent diagnosis. Catatonia has traditionally been thought of as a subtype of schizophrenia (10). Currently there is a need for rigorous adherence to the DSM-III-R criteria for the diagnosis of catatonic schizophrenia. It should not be made on the basis of the presence of catatonic 
alone, but requires a systematic and comprehensive evaluation of the patient with regard to the DSM-III-R criteria.

Ms. H. clearly did not have a history of any chronic psychotic symptomology. However she would consistently identify a stressor that preceded her catatonia. The patient explains the stressor that led to this hospitalization: "I was extremely hurt by my boyfriend's unfaithfulness. I saw him flirting with all these other women and I could not trust him anymore." The patient was able to describe her recent catatonic state as follows: "My whole world caved in and my heart felt heavy with grief and shame. I felt like a bird with clipped wings. I just sit there taking it all in. I'm unable to move or speak. I feel like a frog gets stuck in my throat ... I try to express my feelings but nothing comes out. Like a dummy I sit and stare." The patient reported that at times she was unable to cope with her emotional tensions but would instead express them somatically as catatonia. The patient did not intentionally produce her catatonia. Her symptom was not a culturally sanctioned response pattern, nor could it be explained by any known physical disorder or pathophysiological mechanism. The patient's catatonia is more consistent with conversion disorder than schizophrenia.

The administration of lorazepam had an important role in the treatment of this patient's catatonic symptoms. Recently there have been reports of lorazepam's efficacy in the treatment of catatonia whose etiology is major depression, paranoid schizophrenia (11), catatonic schizophrenia $(12,13)$ and bipolar disorder (14). However, there have been no reported cases of lorazepam specifically being used to treat conversion catatonia. The use of lorazepam in the treatment of conversion catatonia adds an important element in the overall therapeutic approach.

It is extremely important to accurately identify the underlying diagnosis of a catatonic patient. The assumption that catatonia is synonymous with schizophrenia is overly simplistic. The adherence to DSM-III-R criteria can help provide a proper diagnosis in this setting.

\section{REFERENCES}

1. Joseph AB, Anderson WH, O'Leary DH: Brainstem and vermis atrophy in catatonia. Am J Psychiatry 142:352-354, 1985

2. Read SL: Catatonia in thrombotic thrombocytopenic purpura: Case report. J Clin Psychiatry 343-344, 1983

3. Fricchione GL: Neuroleptic catatonia and its relationship to psychogenic catatonia. Biol Psychiatry 20:304-313, 1985

4. Gelenberg AJ, Mandel MR: Catatonic reactions to high-potency neuroleptic drugs. Arch Gen Psychiatry 34:947-950, 1977

5. Johnson GC, Manning DE: Neuroleptic-induced catatonia: Case report. J Clin Psychiatry 44:310-312, 1983

6. Guggenheim FG, Babigian HM: Catatonic schizophrenia: Epidemiology and clinical course. J Nerv Ment Dis 158:291-305, 1974 
7. Ries RK: DSM-III implications of the diagnoses of catatonia and bipolar disorder. Am J Psychiatry 142:1471-1474, 1985

8. Jensen PS: Case report of conversion catatonia: Indication for hypnosis. Am J Psychother 38:566-570, 1984

9. Abrams R, Taylor MA: Catatonia: A prospective clinical study. Arch Gen Psychiatry 33:579-581, 1976

10. American Psychiatric Association: Diagnostic and Statistical Manual of Mental Disorders, Third Edition, Revised. Washington, DC, American Psychiatric Association, 1987

11. Vinogradov S, Reiss AL: Use of lorazepam in treatment-resistant catatonia. J Clin Psychopharmacol 6:323-324, 1986

12. Walter-Ryan WG: Treatment for catatonic symptoms with intramuscular lorazepam. J Clin Psychopharmacol 5:123-124, 1985

13. Heuser I, Benkert O: Lorazepam for a short-term alleviation of mutism. J Clin Psychopharmacol 6:62, 1986

14. Ripley TL, Millson RC: Psychogenic catatonic treated with lorazepam. Am J Psychiatry 145:764-765, 1988 